\title{
Case Study and Randomized Control Trial (RCT) Research Designs for Educational Leadership and Management Studies
}

\author{
Frederick Ebot Ashu \\ Department of Educational Foundations and Administration, Faculty of Education, University of Buea, Cameroon
}

\begin{abstract}
It is becoming increasingly important for researchers to critically reflect on a set of research questions relevant to their own area of research that can have a positive impact on complex social phenomena, such as school leadership and management development outcomes of school leaders. This paper discusses about randomized control trial and case study enables the researcher to answer research questions within the effectiveness of leadership development of Cameroonian school leaders, in the real world, presents new challenges for collecting data and verifying inferences from these data.
\end{abstract}

Many educational leadership researchers seem to have high hopes that such approaches using quasi-experimental, randomized control trails can give positive research outcomes when it comes to educational leadership development of school leaders. It is noted that case study research is more than simply to data collection, analysis, and report writing differing from the traditional, randomized control trial in terms of issues such as rigour, practicality, ethics, sampling, and validity are of great importance and perhaps of special relevance to researchers in Cameroon, and to the African context in which we work. This paper provides a further distinction between randomized control trial and case study research designs. This paper also presents a summary of the different research designs to conduct research in quantitative and qualitative and mixed methods studies.

Keywords: Case Study, Randomized Control Trial (RCT), Research Designs, Educational Leadership, Educational Management

\section{INTRODUCTION}

$\mathrm{I}$ n the most elementary sense, research design is a logical sequence that connects empirical data to a study's initial research questions and ultimately, to its conclusions. According to Creswell (2003) and Yin (1994; 2014), research design means a strategic plan outlining how information is to be gathered for assessment or evaluation (Ebot Ashu, 2014). Researchers, therefore, typically take the position that research design is a plan that guides the decision as to when and how often to collect data; what data to gather and from whom, and how to analyze the data (Ebot Ashu, 2014; Creswell, 2003; Yin, 1994; 2014). Yin (2014) describe the purpose of a research design is to provide a plan of study that permits accurate assessment of cause and effect relationships between independent and dependent variables. Creswell (2003) explains the function of the research design is to ensure that the evidence obtained from either qualitative or quantitative research design enables the researcher to answer the initial question as unambiguously as possible. These researchers are saying there are various designs which are used in social research, all with specific advantages and disadvantages. Much social research is devoted to examining whether a program, treatment, or manipulation causes some outcome or result (Spillane, 2010). Before suggesting any research design much thought was given to factors such as the aims of the study, the nature of the phenomenon, literature on the topic, time scale, feasible data collection, sampling, validity and reliability, ethical issues and so on. Failing to distinguish between design and method for example leads to poor evaluation of designs.

My proposed research as recorded in Ebot Ashu (2014) equate randomized control trials (RCTs) and case studies with (analysis of documents, semi-structured interview and questionnaire), means that the designs are often evaluated against the strengths and weakness of the method rather than their ability to draw relatively unambiguous conclusions or to select between rival plausible hypothesis. Importantly, the selected research designs also referred to scientifically-based research or empirical research is defined by Spillane et al., (2010) as including experimental studies, with preference for RCTs. Empirical research is defined as any research where conclusions of the study is strictly drawn from concretely empirical evidence, and therefore "verifiable" evidence. Creswell (2003) and Yin (1994) added empirical evidence can be gathered using quantitative market research and qualitative market research methods.

As a form of quantitative, research randomized controlled trials are defined by one of the most efficient ways of reducing the influence of external variables. Spillane et al., (2010) draws from (Boruch, 2002; Cook, 2002) argued for more RCT to be conducted in order to evaluate the efficacy of educational leadership interventions despite other researchers are saying RCTs are blunt research designs that ignore context and experience (Connolly et al. 2018); RCTs tend to generate simplistic universal laws of 'cause and effect'; and that they are inherently descriptive and contribute little to theory (Connolly et al. 2018; Boruch, 2002; Cook, 2002).

Case study design, on one the other hand, are often seen as prime examples of qualitative research which adopts an interpretive approach to data, rejects the appropriateness of natural science model for studying human groups and 
organisations behaviours within their context and considers the subjective meanings that the different people or groups and their organisations bring to their situation (Yin, 2003; 2009). As a form of qualitative research, case studies are defined by interest in individual cases, not by methods of inquiry used. Case study research design is an in depth study of a particular situation rather than a sweeping statistical survey. It is a method used to narrow down a very broad field of research into one easily researchable topic.

For the aim of this paper is to showcase how randomised controlled trial (RCT) and a series of case studies were used to determine the impact of two variants of an intervention (a professional development programme) aimed at improving primary school science teachers 'subject and pedagogic content knowledge, and enhancing their subject leadership ability (Muijs et al. 2010). This study uses randomized control trials (RCTs) and case study are viable research design approach to enables educational leadership researcher to answer research questions within the effectiveness of leadership development of school leaders, in the real world, presents new challenges for collecting data and verifying inferences from these data.

\section{Case Study Design}

Yin $(2003 ; 2009 ; 2014)$ defines case study research as empirical inquiry that investigates a contemporary phenomenon within its real-life context; when the boundaries between phenomenon and context are not clearly evident; and in which multiple sources of evidence are used. Case studies are used when the researcher intends to support his/her argument by an in-depth analysis of a person, a group of persons, an organization or a particular project. Whilst it will not answer a question completely, it will give some indications and allow further elaboration and hypothesis creation on a subject. Case study research is a comprehensive, contextual, examination of particular events resulting in the telling of a story that is fuller in detail than in purely scientific statistical analysis. Case Studies draw attention to what specifically can be learned from the cases under review (Yin, 2009; 2014).

"This definition thus cites cases of "decisions" as the major focus of case studies. Other common cases include "individuals, "organisations", "processes, "programs", neighbourhoods", "institutions" and even "events" (p. 17)".

The selection of a specific type of case study design guides the overall purpose of the study. Yin $(2003,2009 ; 2014)$ uses different terms to describe a variety of case studies. Case study research can be based on single- or multiple-case studies; and these in turn can be exploratory, descriptive, or explanatory (Yin, 2003; Ebot Ashu, 2014). Multiple case studies examine several cases in order to understand the similarities and differences between cases. Each of these studies is an in-depth study of the phenomenon of each 'case' in its natural context and including the point of views of the respondents.
In respect to the study that is the subject of this report the use of a multiple case study research design will be adopted. Yin $(2003$; 2014) assert that the logic underlying a multiple case study is that each case must be carefully selected so that it either "(a) predicts similar results (literal replication) or (b) produces contrasting results but for predictable reasons (theoretical replication)" (2003, p. 47).

The research question in this study allows for multiple case studies using a combination of descriptive, exploratory and explanatory types and aiming for theoretical rather than literal replication of results. In school leadership studies case study design methods has been used, for example, by Bolden et al (2003) and Ebot Ashu (2014; 2020). Bolden et al (2003) compared different leadership theories and competency frameworks from the prevailing literature, in a research project that was commissioned to assist the development of the new National Occupational Standards in Management and Leadership". Ebot Ashu (2014; 2020), similarly, explores the factors pertinent to effective school leadership development programmes in a resource poor education system, taking Cameroon as its example. The results in particular indicate that the central educational agencies, schools and school leaders recognised the importance of ensuring that central policies and support, schools' internal policies, and their inservice development opportunities for aspiring head teachers, are closely aligned with international best practice, particularly through the establishment of a structured leadership development programme targeted at aspiring head teachers, and aimed at combining governance skills with a more global outlook. Also, Yu (2007) used multiple case studies contrasting School Effectiveness Research in both developed and developing countries.

This research question and design follows Rhodes et al (2009) and Ebot Ashu (2014). Rhodes' work sought to explore the evidence for the preparedness of NPQH graduates in England for transition to headship through assessing role conceptualisation, initial socialisation, role-identity transformation and purposeful engagement (p.449). The sample comprised a survey of $156 \mathrm{NPQH}$ graduates, followed up by in depth interviews with 15 of these respondents. Rhodes et al. argued that the NPQH has weaknesses, especially in relation to providing a framework within which aspirants heads are enabled to overcome personal and professional difficulties in relation to the transition to headship.

In the case of Ebot Ashu $(2014 ; 2020)$ study is concerned not with universal laws, but with understanding the way in which the individual system leaders at the Cameroon Ministry of Basic Education, schools and school leaders creates, modifies and interprets leadership preparation and management development in preparing aspiring heads for successful school leadership (Commonwealth Secretariat, 1996). The study combines a review of the academic literature with field document analysis evidence, structured interviews with head teachers and teachers, and a Leadership and Management 
Development Questionnaire (LMDQ) study. Using mixed approaches to gather data on school leaderse leadership and management development enables the researcher to validate the effectiveness of leadership and management development interventions using observations from a sub-sample of school leaders. This mixing of data is a unique aspect of the proposed research design. By mixing the datasets, the researcher will be able to present a healthier understanding of the setback than if either dataset had been used alone.

To test the latter preposition, Bush and Jackson (2002) also used case studies, drawing on comparative visits to 15 leadership centres in seven countries, to analyse the type, content and scope of programmes designed to develop skills in school leadership (principally for aspirant leaders but also for new and experienced head teachers). These visits confirmed an international consensus that leadership development occurs at all stages of a person's career; how courses were funded; and the relationship between theories, research and practice was handled in the programmes surveyed. There is, therefore, a body of comparable case study designed research in closely related research areas.

Baxter and Jack (2008) state that "once the case has been determined and the boundaries placed on the case it is important to consider the additional components required for designing and implementing a rigorous case study" (p. 550). These components are the "propositions" which the case study seeks to test, and these may come from the literature (Yin, 2003, Miles \& Huberman, 1994; Yin, 2009); the application of a conceptual framework (Miles and Huberman, 1994) and development of the research questions (generally "how" and/or "why" questions).

The propositions below subsequently guide the design; determine the direction and scope of the study and form the foundation of the conceptual framework that guides the research. The study which forms the basis of this report identifies a number of propositions that must be returned to when analyzing the data and reporting the findings (see Table 1, below):

Table 1: Case Study Propositions

\begin{tabular}{|l|c|}
\hline Potential Propositions & $\begin{array}{c}\text { Source (These are only examples } \\
\text { of literature and do not reflect a } \\
\text { full literature review). }\end{array}$ \\
\hline $\begin{array}{l}\text { How effective are leadership and } \\
\text { management development } \\
\text { programmes in Cameroon in }\end{array}$ & $\begin{array}{c}\text { Yu (2007) } \\
\text { Rhodes et al (2009) } \\
\text { preparing prospective leaders to } \\
\text { Become high quality leaders } \\
\text { supporting school effectiveness } \\
\text { and organisational systems? }\end{array}$ \\
& Ebot Ashu (2014) \\
& Ebot Ashu (2018) \\
& Ebot Ashu (2020) \\
Republic of Cameroon (1998) & Republic of Cameroon. (2001; \\
\hline
\end{tabular}

Propositions form the basis for the design phase of the research in which the researcher determines the criteria and the approaches to be used. In case studies careful case selection and the use of research tools and methods that are appropriate to addressing the proposition(s) have a significant influence on the eventual validity of the study. Central to this is also the use of appropriate data collection methods which are able successfully to elicit and record information relevant to the propositions that can then be analysed and evaluated.

\section{RESEARCH METHODS}

The overall research questions form the basis for the design phase of the research in which the researcher determines the criteria and the approaches to be used. In qualitative mixed method designs careful selection of cases, research tools and data collection methods that are appropriate to addressing the theoretical proposition(s) have a significant influence on the eventual validity of the study. In relation to the design of my own research Fig 1 outlines the fundamental research design against which backdrop decisions about the research tools and data collection methods must be arrived at.

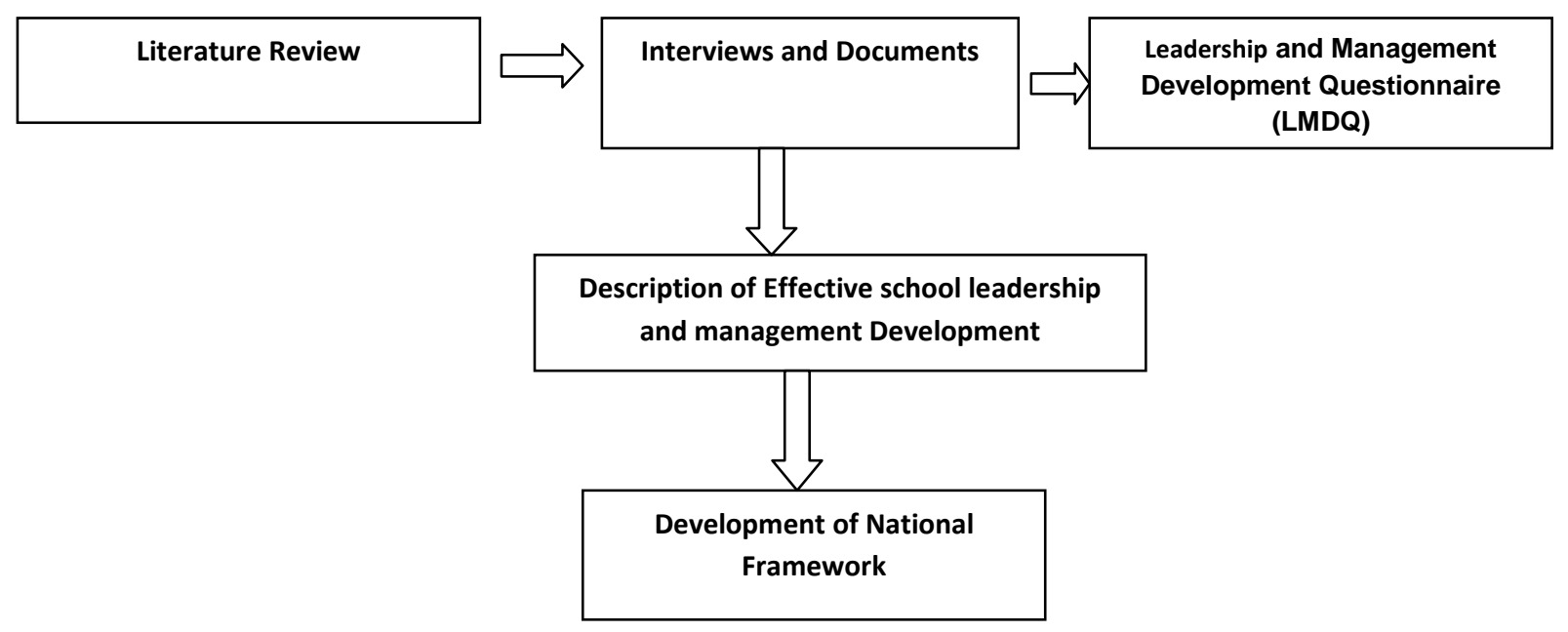

Fig 1: Study Design 
Fig 1 explains how the study reviewed relevant literature pertaining to leadership and management development interventions and how these are integrated with interviews, documentary evidence and a questionnaire to ultimately provide the material enabling the researcher to describe effective school leadership and thereby arrive at conclusions and recommendations.

The integrated analysis in the case study was carried out, specifically, through analysis of training processes, analysis of leadership performance data, analysis of the learning logs (LMDQ, interviews, documents), and data analysis.

The training processes relating to leadership performance is analysed through a combination of interviews and documentary data from the Cameroon Ministry of Basic Education, learning logs across the six case study sites and data analysis making use of the LMDQ.

Ebot Ashu (2014) and Earley et al's (2002) study provides a model in terms of analysing leadership performance data, whereby a sample can be selected and analysed to inform the evaluation and screening of descriptive variables related to the sample characteristics, including respondents' current position, type of school, length of service, their gender and age and levels of education and training attained. These variables is analysed using frequency distributions and crosstabulations.

Thirdly, learning logs of education and training at a school level (following Rhodes et al, 2009 and Ebot Ashu, 2014), and at an educational system level (following Bush and Jackson, 2002 and Ebot Ashu, 2014), utilising the LMDQ model of learning log questionnaires, enable complex data analysis using an appropriate Statistical Package for the Social Sciences (SPSS Version 15.0). A range of descriptive and inferential statistical tests will be deploying to handle and analyse the data.

Providing recommendations for effective leadership and management development standards also required the collection of interviews and documentary data to allow the study of the needs of Cameroon school leaders (Bush, 2008). To ensure the validity of the processes in this research, the interviews were recorded and transcribed word for word and field notes will also be written at the time of interviewing to enhance the quality of the data. Interviews and documentary data collection and data analysis closely followed the approach of Miles and Huberman (1994). This strategy allow the researcher to check hypotheses as they emerge from data analysis and thereby to refine data collection strategies as the study progresses.

Documentary and interview data was analysed using content analytic methods (Neuendorf, 2002). A coding scheme was developed and results quantified. In particular the analysis of the interview data follows the high-performance leadership competency model adopted in Rhodes et al (2009) and Ebot Ashu (2014). Rhodes et al's survey of NPQH graduates reviews the subjective opinions of the graduates as to their preparedness for headship, and seeks to temper the subjectivity of the research outcomes by using a 'Wilcoxon Signed Rank Test' to analyse perceptions of preparedness with respect to each facet of the NPQH taught elements. They then further analyse this data using a 'Kruskal-Wallis Test' to analyse any difference between the respondent sub groups in their perceptions of preparedness with respect to each of the facets (p. 453).

For the analysis of the LMDQ data, Ebot Ashu (2014) Rating Scale Model, which applies to Likert scale surveys, was used to analyse the data regarding the usefulness of the 30 units of study in the context of respondent informal on the job training. In the Likert scale, each unit of study was accompanied by a five-position scale and the respondent had to mark a response for each item on the provided continuum in order to show its perceived degree of usefulness. Ebot Ashu model involved transforming the count of the endorsements of the ordered Likert categories into several interval scales. Thus Ebot Ashu's model of Likert scale analysis offered a thorough mathematical opinion to additional innovative approaches of rating scale analysis that require mainly summarizing results in the form of means scores interpretations.

Overall, this proposed study therefore follows Earley et al (2002) and Ebot Ashu (2014) in combining survey approaches to gathering data on school leaders' knowledge of leadership and management training interventions with interview approaches that involve the initial evaluation of primary and secondary documents and policies from the Cameroon Ministry of National (Basic) Education and six case study schools.

Using mixed approaches to gather data on school leaders' leadership and management development enables the researcher to validate the effectiveness of leadership and management development interventions using observations from a sub-sample of school leaders. This mixing of data is a unique aspect of the proposed research design. By mixing the datasets, the researcher is able to provide a better understanding of the problem than if either dataset had been used alone. Thus, the data generated through aspiring school leaders LMDQ $\operatorname{logs}$ will be validated with reference to the head teacher LMDQ learning logs. Each of these will then be further validated through the interviewing process and documents collected.

This is in essence a process of triangulation (described by Hammersley and Atkinson (1989) as the use of two or more methods of data collection (multiple methods) in the study as "the major means of validating some aspect of human behaviour."). Here, combining data generated from the case survey both allows the data to be validated and informs any subsequent redesign process (as alluded by Bush and Jackson, 2002; Rhodes et al, 2009; Ebot Ashu, 2014; 2020).

\section{The Ethical Issues in Case Study Research}

Ethical considerations were given the highest importance in that informed consent was sought from all the samples and 
their gatekeepers. Permission was obtained, from the Cameroon Ministry of National Education body which approves and oversees any research done by citizens and noncitizens from foreign organisations and institutions. Care was also taken to inform internal and external stakeholders on the purposes of the study and the extent of their involvement as participants and that audio-recording would be used but their identities would be safeguarded and the reporting would be done in anonymity. The British Educational Research Association (BERA, 2004) guidelines will be adhered to in order to ensure respect for each person, knowledge, democratic values, the quality of educational research and academic freedom.

\section{Randomized Control Trial (RCT)}

Rrandomized control trials are a form of research that represents one of the most efficient ways of reducing the influence of external variables on the subject under research. Spillane et al (2010) state that randomized controlled trials are used to examine the effect of interventions on particular outcomes, and, following Boruch, 2002; Cook, 2002; Eisenhart and Towne, 2003, they argue for more RCTs to be conducted in educational research as a means of evaluating the efficacy of educational interventions. They go on to argue that there are three core principles or assumptions in RCTs, these being "randomization, control, and comparison". For Spillane et al. "treatments are assigned randomly to subjects, treatments are controlled, and comparison of control and treatment groups enables..." (p.7) the researcher to detect a treatment effect.

Yin (2009) states that RCTs are undertaken when an investigator can manipulate behaviour directly, precisely, and systematically. A particular challenge with using RCTs outside a "laboratory" environment, according to Spillane et $a l$. , is that in the real world "human and socio-political factors interact with assignments and treatments" (p.7). These interactions risk undermining the core "controlled" nature of RCTs. In the field of evaluation research, (Spillane et al, 2010), has made a compelling argument for the practicality of field experiment-randomized control trial design (Yin, 2009; 2014)

The authors maintain that the field trials design, emulating the design of laboratory experiments, can be and has been used even when evaluating complex community initiatives. However, you should be cautioned about the possible limitations of this design (p. 12).

The work of Yin and of Spillane et al. suggests that a RCT research design may work well where individual school leaders, or users of the leadership and management development interventions, are the unit of analysis. Such a situation would exist if school leadership development interventions consisted, say, of effective school leadership and management development interventions, and the outcomes of interest was the incidence of certain interventions that enhance school leaders' performance or organisational systems supporting students achievements. The random assignment might designate a few school leaders in different schools to have the leadership and management development interventions, compared to a few that did not, and the outcomes would compare the condition of school leaders in both sets of schools.

A particular advantage of the RCT design for this study is the ability to incorporate the outcomes of interest, and therefore define what the appropriate units of analysis are (Yin, 2009). Additional advantages include being able to arrive at a fuller understanding of the factors influencing school leaders' through being able to analyse how the particular "treatments" within the RCT interact with the leadership outcomes.

The randomized control trial in this current research will involve a design in which different school leaders in Cameroon are randomly assigned to participate in early or delayed treatment groups. In adopting the kind of iterative process advocated by Spillane et al. for my research it is recognised that randomized controlled trials represent a powerful tool in modern leadership development studies, because the act of randomizing aspiring school leaders and head teachers to receive or not receive the intervention ensures that, on average, all other possible causes are equal between the two groups (Boruch et al. 1978). Thus, any significant differences between groups in the outcome event can be attributed to the intervention and not to some other unidentified factor.

It should be noted, however, that, although respondents from different schools will be randomly assigned, the degree of freedom in any statistical analysis is limited to the number of schools in Cameroon rather than the number of school leaders. This study was unable to support the participation of a sufficiently large number of schools to overcome the severity of the subsequent statistical constraints (Yin, 2009; Spillane et al., 2010).

RCTs, however, are not a solution to answer all school leadership development enquiries. For example, if head teachers in Cameroon, demonstrate better leadership and management development skills than aspiring school leaders we cannot attribute this difference in leadership performance straightforwardly to organisational systems. Because school leaders are randomised to the treatment (combining aspiring school leaders and head teachers) we cannot be confident that the two groups were similar at the outset.

Furthermore, in many situations, randomized controlled trials are not feasible, necessary, appropriate, or even sufficient to help solve important problems. RCTs may not be appropriate for assessing the leadership development of school leaders in Cameroon due to the long delay between initiation and outcome. Thus, although the trial for appraising the ultimate value of school leader's leadership development experiences may be a large well-designed RCT that has school leader's leadership development outcomes as the end point, the trial should presumably be performed after other smaller studies 
have examined the predictive value of the test against some accepted standard.

An excellent example of the controversies that can arise with RCTs is an overview of theory-driven evaluation through which theories about the relationships between a programme's treatment variables and outcome variables guide the design of the RCT. The most important references concern the article by Spillane et al., (2010). The logic model developed by Spillane (see Fig. 2) explains that head teachers may acquire new knowledge and skills through participation in the leadership development intervention programme; but what aspiring school leaders learn will depend on both the content and pedagogy of the programme they attend, and their background. In turn, both school leaders' new knowledge and skills will contribute to changes in school leadership practice, effecting most change in those school conditions which are conducive to leadership (e.g., presence of trust, collective responsibility, confidence, positive attributes etc.).

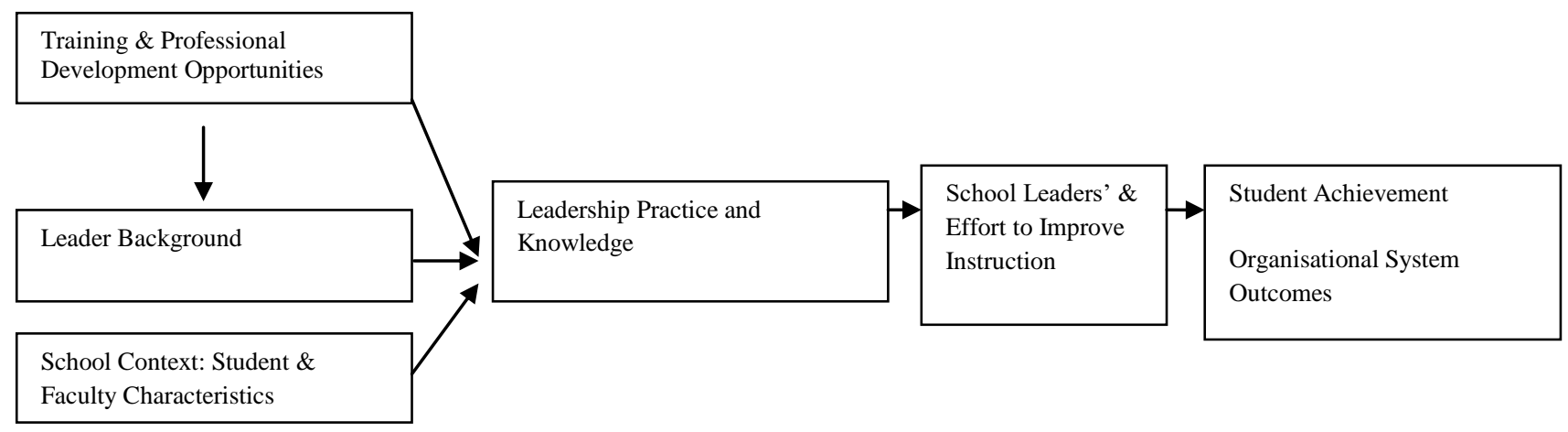

Fig 2. A Logic Conceptual Framework adapted from Spillane et al., (2010).

In Spillane et al's logic model, aspiring school leaders' knowledge and practice are the expected outcomes and student achievement and organisational systems is a possible outcome. At the same time, aspiring school leaders' professional development opportunities are a mediating variable between the treatment and school leader's practice. Further, relations between the treatment and student achievement plus organisational systems will be mediated not only by school leaders' knowledge and practice but also by school level conditions and classroom teaching.

RCTs may not be appropriate for the assessment of interventions that have rare outcomes or effects that take a long time to develop, and in which there may therefore be significant uncontrolled mediating variables. In such instances, other study designs such as case-control studies or cohort studies may be more appropriate (Yin, 2009; Spillane et al, 2010). In other cases, RCTs may not be feasible because of financial constraints or because of the expectation of low compliance or high drop-out rates of school leaders.

Many RCTs involve large sample sizes because many treatments have relatively small effects. The size of the expected effect of the leadership and management development intervention is the main determinant of the sample size necessary to conduct a successful randomized controlled trial. Obtaining statistically significant differences between two samples (aspiring school leaders and head teachers) is easy if large differences are expected. However, the smaller the expected effect of the intervention, the larger the sample size needed to be able to conclude, with enough power, that the differences are unlikely to be due to chance.
The RCT design may incorporate different phases in the evaluation of different interventions, including explanatory or pragmatic trials and efficacy or effectiveness trials:

\section{Explanatory or pragmatic trials}

When defining the research question I have to consider whether to ask a pragmatic or an explanatory question. This will have important implications for the study design. Explanatory trials are designed to answer a simple question: e.g. do the leadership and management development programmes in Cameroon succeed in preparing prospective leaders to become effective leaders? If they do, then the trial attempts to establish how this works. Pragmatic trials, on the other hand, are designed not only to determine whether the intervention works but also to describe all the consequences of the intervention and its use under circumstances corresponding to daily practice. Although both explanatory and pragmatic approaches are reasonable for my study, and even complementary, as alluded by Spillane et al and Yin, it is important to understand that they represent extremes of a spectrum, and most RCTs combine elements of both.

The distinction between pragmatic and explanatory research is important, however, because it will determine key methodological issues relating to school leaders' selection, definition of the intervention and controls, the avoidance of bias, choice of outcome measure and type of analysis.

\section{Efficacy or Effectiveness Trials}

The study similarly considered a research design that evaluates the efficacy or effectiveness of an intervention. Efficacy refers to interventions carried out under ideal circumstances, as it answers the question "can the suggested 
interventions work?", whereas effectiveness evaluates the effects of an intervention under circumstances similar to those found in school leaders' daily practice (Spillane et al, 2010). It answers the question, "does the intervention work?"

Drawing this together, the study therefore will follow Spillane et al. in combining approaches to evaluate interventions. Four phases of trial could be incorporated in the design to evaluate the impact of the interventions. Phase 1, 2, 3, and 4 trial. These terms describe the different types of trials used for the introduction of a new leadership development intervention for aspiring school leaders.

In Phase 1, studies are usually performed on both aspiring school leaders and head teachers. Once the intervention passes phase 1 , phase 2 begins. The intervention, in this case, is given to a purposive sample of 24 school leaders, in six case study schools and the purpose of this study is to evaluate the efficacy of different modes of administration of the intervention to school leaders. Phase 2 studies focus on efficacy while still providing information on the appropriateness of the leadership and management development interventions. Phase 3 studies are typically effectiveness trials, which are performed after a given procedure has been shown to demonstrate that the leadership and management development interventions have a reasonable chance of improving school leader's performance. Most phase 3 trials are RCTs. Phase 4 studies are equivalent to post marketing studies of the intervention; they are performed to identify and monitor possible adverse events not yet documented. This type of RCT may incorporate crossover, and factorial designs.

\section{Crossover Design}

Crossover design could be incorporated in this design because participants will be given all of the study interventions in successive periods. The order in which the participants receive each of the study interventions is determined at random (Klemp, 1980; Spillane et al, 2010). This design, obviously, is appropriate mostly for measuring the development of aspiring school leaders' leadership and management performance in a situation that is fairly stable over time and for interventions that last a short time with school leaders in specific schools and that do not interfere with one another. Otherwise, false conclusions about the effectiveness of an intervention could be drawn.

\section{Factorial design}

The proposed study may similarly incorporate factorial design because two or more experimental interventions are not only evaluated separately but also in combination and against a control. The proposed study may follow Spillane et al (2010), for example, in incorporating a $2 \times 2$ factorial design which generates three sets of data to analyze: data on school leaders who received none of the interventions, school leaders who received treatment $A$, school leaders who received treatment $\mathrm{B}$, and school leaders who received both $\mathrm{A}$ and B. More complex factorial designs, involving multiple factors, are occasionally used. The strength of this design is that it provides more information than any other design. In addition to the effects of each treatment, factorial design allows evaluation of the interaction that may exist between two treatments.

RCTs can be performed in one or many schools and can include from one to thousands of participants, and they can have fixed or variable (sequential) numbers of participants. This main thesis may utilize a fixed trial, whereby the investigators establish deductively the number of participants (sample size) that will be studied. This number can be decided arbitrarily or can be calculated using statistical methods. The latter is a more commonly used method. Even in a fixed trial, the design of the trial usually specifies whether there will be one or more interim analyses of data. If a clear benefit of one intervention over the other can be shown with statistical significance before all participants are recruited, it may not be ethical to pursue the trial, and it may be prematurely terminated.

\section{The Ethics of Randomized Controlled Trials}

Despite the claims of Spillane et al insisting that RCTs are the best way of evaluating the effectiveness of leadership development interventions, others have warned that before a RCT can be conducted there must be genuine doubt about whether one course of action is better than another (Yin, 2009). The idea behind this method is the state of knowledge in which no evidence exists that shows that any intervention in the trial is better than another and that any intervention is better than those in the trial. The review generalised that it is not ethical to build a trial in which, some school leaders are engaged in some interventions and others are not. Yin described that school leaders who engaged in the study are more likely to benefit from the new intervention than school leaders who do not. RCTs can be planned only in areas of uncertainty and can be carried out only as long as the uncertainty remains.

\section{SUMMARY AND CONCLUSIONS}

This study has set out a first attempt to present two separate designs. It has been shown that case study research is more than simply conducting research on a single individual or situation. The selected approach, using multiple case studies, has the potential to deal with both simple and complex situations. It enables the research to answer the research question while taking into consideration how a phenomenon is influenced by the context within which it is situated.

Evaluating interventions designed to influence complex social phenomena, such as the effectiveness of the leadership development of Cameroonian school leaders, in the real world, presents new challenges for collecting data and verifying inferences from these data.

This paper, however, shows how randomized controlled trials are one of the most effective experimental methods of research. It is argued that the proposed research will benefit 
from employing a complex research design and analytic strategy, employing both case study evaluation and RCTs which will provide a wide range of triangulated evidence (both within each individual design, and across the two designs) from which it will be possible to draw valid and robust conclusions. Further, it is argued that the suggested design benefits from employing interpretive as well as positivist methods. Given the emerging status of RCTs in evaluation studies of educational interventions, using mixed methods for collecting and analyzing data not only adds rigour to the conclusions produced by such studies but also can increase the returns from such evaluations in the form of knowledge related to methods and measure validation and core constructs.

\section{REFERENCE}

[1] Baxter, P. and Jack, S. (2008). Qualitative Case Study Methodology: Study Design and Implementation for Novice Researchers. The Qualitative Report, 13 (4), 544-559.

[2] BERA, British Educational Research Association (2004). Revised Ethical Guidelines for Educational Research. Macclesfield: BERA.

[3] Bolden, R., Gosling, J., Marturano, A., Dennison, P. (2003). A Review of Leadership Theory and Competency Frameworks. Edited Version of a Report for Chase Consulting and the Management Standards Centre. Exeter: University of Exeter, Centre for Leadership Studies.

[4] Boruch, R. (2002). The Virtues of Randomness. Education Next. 2(3), 36-42

[5] Boruch, R., McSweeny., and Soderstrom, E. (1978). Randomized Field Experiments for Program Planning, Development, and Evaluation. Evaluation Quarterly, 2 (4), 655-695

[6] Bush, T. (2008). From Management to Leadership. Semantic or Meaningful Change?. Educational Management, Administration \& Leadership. London: Sage.

[7] Bush, T. and Jackson, D. (2002). A Preparation for School Leadership: International Perspectives. Education Management and Administration, 30 (4), 417-429.

[8] Connolly, P.; Keenan, C.; \& Urbanska, K. (2018). The trials of evidence-based practice in education: a systematic review of randomized controlled trials in education research 1980-2016, Educational Research, 60(3), 276-291, DOI: 10.1080/00131881.2018.1493353

[9] Cook, T. D. (2002). Randomized experiments in educational policy research: a critical examination of the reasons the educational evaluation community has offered for not doing them. Educational Evaluation and Policy Analysis, 24(3), 175-199.

[10] [Commonwealth Secretariat. (1996). Better Schools: Resource Materials for Heads: Introductory Module. London: Commonwealth Secretariat.

[11] Creswell, J. (2003). Research Design: Qualitative, Quantitative, and Mixed Method Approaches. Thousand Oaks, Calif.: Sage Publications.

[12] Earley, P., Evans, J., Collarbone, P., Gold, A. and Halpin, D. (2002). Establishing the Current State of School Leadership In England. London, UK: Institute of Education University of London.

[13] Ebot Ashu, F. (2020). Decolonizing Educational Leadership and
Administration Curriculum at Cameroonian Universities. African Journal of Education and Practice (AJEP). 6 (5), 13 - 39.

[14] Ebot Ashu, F. (2014). Effectiveness of School Leadership and Management Development in Cameroon: A Guide for Educational Systems, Schools and School Leaders. Newcatle Upon Tyne, United Kingdom: Cambridge Scholars Publishing. http://www.amazon.co.uk/Effectiveness-Leadership-ManagementDevelopment-Cameroon/d p/1443855820.

[15] Ebot Ashu, F. (2018). Leadership, Management and Administrative Roles of School Leaders in Cameroon, International Studies in Educational Administration, 46(2), 110128.

[16] Eisenhart, M., \& Towne, L. (2003). Contestation and change in national policy on "scientifically based" education research. Educational Researcher, 32(7), 31-38.

[17] Hammersley, M., and Atkinson, P. (1989). Ethnography: Principles in practice. London: Routledge.

[18] Klemp, G. O. (1980). The Assessment of Occupational Competence. Washington, DC: Report to the National Institute of Education

[19] Miles, M. B., \& Huberman, A. M. (1994). Qualitative data analysis: An expanded source book (2nd ed.). Thousand Oaks, CA: Sage.

[20] Muijs, D., Chapman, C., Colins, A., Armstrong, P. (2010). Maximum Impact Evaluation. The Impact of Tech First Teachers in Schools. AN Evaluation funded by the Maximum Impact Programme for Tech First Report. Manchester: The University of Manchester.

[21] Neuendorf, K. (2001). The Content Analysis Handbook. Thousand Oaks: Sage.

[22] Republic of Cameroon. (2011). Growth and Employment Strategy Paper (GESP). Yaounde: Presidency of the Republic.

[23] Republic of Cameroon. (1998). Law No. 98/004 of 14 April to lay Down Guidelines for Education in Cameroon. Yaounde: Presidency of the Republic.

[24] Republic of Cameroon. (2001). Law No. 005 of 16 April 2001 to Guide Higher Education in Cameroon. Yaoundé: Imprimerie Nationale.

[25] Rhodes, C., Brundrett, M., Nevill, A. (2009). Just the Ticket? The National Professional Qualification and the Transition to Headship in the East Midlands of England. Educational Review, 61 (4), 449468.

[26] Spillane, J., Pareja, A., Dorner, L.., Barnes, C., May, H., Huff, J., Camburn, E. (2010). Mixing Methods in Randomized Controlled Trials (RCTs): Validation, Contextualization, Triangulation, and Control. Educational Assessment Evaluation and Accountability, 22(1), 5-28.

[27] Yin, R. K. (2003). Case study research: Design and methods (3rd ed.). Thousand Oaks, CA: Sage.

[28] Yin, R. K. (2009). Case Study Research Design Methods, Fourth Edition. Applied Social Research Methods Series. Thousand Oaks, CA: SAGE.

Yin, R. K. (2014). Case Study Research Design and Methods (5th ed.). Thousand Oaks, CA: Sage.

[29] Yin, R. K., (1994). Case Study Research Design and Methods: Applied Social Research and Methods Series. Second edn. Touand Oaks, CA: Sage Publications Inc.

[30] Yu, G. (2007). Research Evidence of School Effectiveness in SubSaharan Africa. EdQual Working Paper No. 7. Bristol, UK: University of Bristol, UK. 